EGU2020-13719, updated on 10 Jun 2021

https://doi.org/10.5194/egusphere-egu2020-13719

EGU General Assembly 2020

(c) Author(s) 2021. This work is distributed under

the Creative Commons Attribution 4.0 License.

\title{
Large-scale controls of soil organic carbon in (sub)tropical soils
}

Sophie F. von Fromm ${ }^{1,2}$, Alison M. Hoyt ${ }^{1}$, Asmeret Asefaw Berhe ${ }^{3}$, Keith D. Shepherd ${ }^{4}$, Tor-Gunnar Vågen ${ }^{4}$, Leigh A. Winowiecki ${ }^{4}$, Lulseged T. Desta ${ }^{5}$, Jerome E. Tondoh ${ }^{6}$, Andrew M. Sila ${ }^{4}$, Erick K.

Towett ${ }^{4}$, Elvis Weullow ${ }^{4}$, Ermias Aynekulu ${ }^{4}$, Johan Six ${ }^{2}$, Susan E. Trumbore ${ }^{1}$, and Sebastian Doetterl ${ }^{2}$

'Department of Biogeochemical Processes, Max-Planck-Institute for Biogeochemistry, Jena, Germany (sfromm@bgc-

jena.mpg.de)

${ }^{2}$ Department of Environmental System Science, ETH Zurich, Switzerland

${ }^{3}$ University of California Merced, USA

${ }^{4}$ International Centre for Research in Agroforestry, Nairobi, Kenya

${ }^{5}$ International Centre for Tropical Agriculture, Addis Ababa, Ethiopia

${ }^{6}$ Université Nangui Abrougoua, Abidjan, Côte d'Ilvoire

Soil organic carbon (SOC) is a key component of terrestrial ecosystems. Experimental studies have shown that soil texture and geochemistry have a strong effect on carbon stocks. However, those findings primarily rely on data from temperate regions or use model approaches that are often based on limited data from tropical and sub-tropical regions.

Here, we evaluate the controls on soil carbon stocks in Africa, using a dataset of 1,580 samples. These were collected across Sub-Saharan Africa (SSA) within the framework of the Africa Soil Information Service (AfSIS) project, which was built on the well-established Land Degradation Surveillance Framework (LDSF). Samples were taken from two depths $(0-20 \mathrm{~cm}$ and $20-50 \mathrm{~cm})$ at 46 LDSF sites that were stratified according to Koeppen-Geiger climate zones. The different $\mathrm{pH}$ values, clay content, exchangeable cations and extractable elements across various soils of the different climatic zones (i.e. from arid to humid (sub)tropical) allow us to identify different soil and climate parameters that best explain SOC variance across SSA.

We tested if these SOC predictors differed across climatological conditions, using the ratio of potential evapotranspiration (PET) to mean annual precipitation (MAP) as indicator. For waterlimited regions (PET/MAP > 1), the best predictors were climatic variables, likely because of their effect on the quantity of carbon inputs. Geochemistry dominated SOC storage in energy-limited systems (PET/MAP $<1$ ), reflecting its effect on carbon protection. On a continental scale, climate (e.g. PET) is key to predicting SOC content in topsoil, whereas geochemistry, particularly ironoxyhydroxides and aluminum-oxides, is more important in subsoil. Clay content had little influence on SOC at both depths. These findings contribute to an improved understanding of the controls on SOC stocks in tropical and sub-tropical regions. 